\title{
Manual do Estagiário e Portaria de Estágio: Elementos de Unidade na Diversidade do Estágio Curricular da FE-USP
}

\author{
Renato Melo Ribeiro e Afonso Martins Andrade \\ Faculdade de Educação da Universidade de São Paulo
}

* Autor para correspondência: renatoribeiro@usp.br

\section{RESUMO}

Este relato de experiência tem por objetivo apresentar brevemente duas importantes iniciativas desenvolvidas no âmbito do Programa de Formação de Professores da Faculdade de Educação da USP: o Manual do Estagiário e a portaria de estágio. Estas duas realizações fazem parte de um mesmo processo de sistematização da estrutura, do funcionamento, das normas e dos procedimentos relativos ao estágio curricular obrigatório na unidade. Nesse processo, o presente trabalho também tece considerações sobre a importância do referido manual e da portaria para uma faculdade com enorme quantidade de estagiários e grande diversidade de propostas e práticas de estágio.

Palavras-Chave: Estágio Curricular; Manual do Estagiário; Portaria de Estágio.

\begin{abstract}
This experience report is meant to present briefly two important initiatives developed in the context of Teacher Development Program at the Faculdade de Educação da USP: the Manual of the Intern and its regulations about the internship. Both of these achievements are part of the same systematizing structural process, its functioning, its rules and the procedures related to the internship program compulsory at the school. In this process, the present work also remarks about the importance of the manual and its regulation in a institute that has a variety of interns and a diversity of proposals for internship practices.
\end{abstract}

Keywords: Internship Programs; Manual of the Intern FEUSP; Internship Regulation.

\section{Manual do Estagiário}

O Manual do Estagiário ${ }^{1}$ foi elaborado pela equipe de educadores e monitores do Programa de Formação de Professores da Faculdade de Educação da USP (PFP-FEUSP) no primeiro semestre de 2015, para oferecer orientações gerais sobre o estágio curricular obrigatório e sobre a inserção nas escolas públicas enquanto campo prioritário de estágio.

Pensado para ser uma ferramenta de consulta para todos os estagiários da FEUSP que precisam familiarizar-se com normas, disciplinas, seções e serviços específicos relacionados aos estágios, o Manual do Estagiário também traz recomendações para a entrada e a permanência do estagiário na escola, em função das especificidades da dinâmica e do contexto escolar, além de informações úteis como links para pesquisa e até um glossário com as siglas mais utilizadas nas redes oficiais de ensino.

Destacam-se também no referido manual as informações sobre o estágio curricular obrigatório a partir da Lei n. 11.788/2008, da resolução do Conselho Nacional de Educação (CNE/CP n. 2/2002) que dispõe sobre a carga horária de estágio, e da deliberação do Conselho Estadual de Educação (CEE n. 111/2012 e CEE n. 126/2014) que fixa diretrizes curriculares complementares para a formação docente no Estado de São Paulo. 
A partir das diretrizes do Programa de Formação de Professores $(2004)^{2}$ e dos projetos pedagógicos da Pedagogia e demais licenciaturas ${ }^{3}$, a publicação descreve o funcionamento do estágio curricular na FEUSP, que conta com o trabalho de educadores da área de formação de professores (servidores da faculdade) e de monitores-bolsistas (pós-graduandos da USP) no apoio aos docentes e licenciandos vinculados a disciplinas acadêmicas com carga horária obrigatória de estágio.

Além disso, o manual teve o cuidado de responder as dúvidas mais frequentes dos estagiários: onde os licenciandos podem realizar seus estágios; quantas horas de estágio podem fazer por dia; se há ou não dispensa do estágio curricular para quem já faz estágio remunerado ou exerce a função docente; se há dispensa em caso de gestação ou doença; como funciona o seguro em caso de acidente; se é possível integralizar estágios de diferentes disciplinas na mesma escola, entre outras questões.

Para a concretização do Manual do Estagiário foi fundamental o apoio da Comissão Coordenadora do Curso de Pedagogia (CoCPedagogia), da Comissão Coordenadora do Curso de Licenciaturas (CoC-Licenciaturas) e da Comissão de Graduação (GG) da unidade. Além do indispensável apoio institucional, o reconhecimento dessa iniciativa pioneira na USP é notável, tanto para os licenciandos como para os demais agentes (dirigentes, docentes e servidores) da FEUSP.

\section{Portaria de Estágio}

A produção do Manual do Estagiário demandou iniciarmos uma pesquisa sobre legislação, resoluções, decretos e portarias de estágio curricular obrigatório, incluindo um levantamento sobre decisões da Comissão de Estágio da FEUSP em relação a recursos dos estudantes. Com as informações levantadas, foi possível sugerir a modificação de documentos importantes do estágio na FEUSP - o Termo de Compromisso e a Ficha de Estágio.

No primeiro semestre de 2017, a partir das pesquisas e sistematização feitas, visto que as 130 informações estavam distribuídas em inúmeros documentos, apresentamos à Faculdade um único documento com normas e procedimentos relativos ao estágio curricular obrigatório, que, por sugestão da Comissão de Graduação (CG), foi transformado em proposta de Portaria de Estágio ${ }^{4}$, consolidando as normativas e procedimentos em vigor na FEUSP.

O texto da Portaria explicita a vinculação das horas de estágio a um conjunto de disciplinas obrigatórias, ao longo da licenciatura. A Faculdade de Educação é responsável por trezentas horas de estágio das 32 licenciaturas que cursam as disciplinas pedagógicas oferecidas pela unidade, e também por 420 horas de estágio da licenciatura em Pedagogia.

Segundo a portaria, o estágio curricular na FEUSP deverá ser realizado principalmente em escolas de Educação Básica e prioritariamente em escolas públicas. A depender da disciplina, o estágio poderá abranger outros espaços públicos relevantes para a Educação Básica, como órgãos intermediários e centrais de educação, museus, centros de formação etc.

Estudantes que realizam estágio remunerado em instituição de Educação Básica e mesmo aqueles que já exercem a função docente não estão dispensados do estágio obrigatório, dada a vinculação da carga horária de estágio com os conteúdos teóricos específicos das disciplinas. Mesmo em caso de gestação ou doença, não há dispensa do estágio, mas tão somente protelação da realização do mesmo, conferindo tratamento excepcional.

A portaria estabelece uma divisão de responsabilidades entre três importantes setores que lidam com os estágios curriculares: a Seção de Estágios, o Programa de Formação de Professores e a Comissão de Estágios. Cabe à Seção de Estágios um papel mais administrativo e documental, fornecendo os termos de compromisso e as fichas de estágio, entre outras questões mais formais do estágio. Por sua vez, os educadores e monitores do Programa de Formação de Professores auxiliam os docentes responsáveis pelas disciplinas no acompanhamento 
dos projetos de estágio em escolas públicas parceiras, além de assessorarem o trabalho das comissões coordenadoras de curso da unidade. Já a Comissão de Estágios é responsável, entre outras atribuições, pela análise dos recursos e requerimentos dos licenciandos em relação à questão dos estágios, assessorando a Comissão (CG).

Por fim, a Portaria de Estágio da FEUSP consolida o Manual do Estagiário como instrumento de comunicação de sua política de estágio, inclusive para dar publicidade às diretrizes, às regras e aos procedimentos estabelecidos no seu corpo normativo, responsabilizando as comissões coordenadoras de curso (com apoio técnico dos educadores do Programa de Formação de Professores) pela revisão e atualização periódica da publicação.

\section{Considerações Finais}

Para uma faculdade com mais de 3 mil estagiários por semestre, oriundos de 33 licenciaturas diferentes e que cursam disciplinas pedagógicas com mais de cinquenta docentes, não é surpreendente a existência de uma grande diversidade de práticas e políticas de estágio curricular obrigatório. Se, por um lado, essa diversidade representa uma riqueza acadêmica, também expressava uma relativa dispersão e fragmentação pedagógica, com políticas de estágio definidas muito mais em cada disciplina do que no nível da instituição como um todo.

Nesse sentido, tanto a Portaria de Estágio como o Manual do Estagiário são importantes elementos de unidade nessa diversidade do estágio curricular da FEUSP. Primeiro, por proporcionar o estabelecimento de diretrizes, normas e procedimentos comuns no estágio obrigatório; e segundo, por dar ampla visibilidade a todas essas definições, construídas por um importante processo de sistematização, discussão e construção coletiva.

Por fim, esperamos que a experiência aqui relatada, bem como as reflexões desenvolvidas possam inspirar iniciativas similares em outras unidades da USP (e de outras instituições de ensino superior). Tanto o manual como a portaria valorizam sobremaneira o estágio como parte indissociável da formação de futuros professores.

\section{Notas}

1 Disponível em: http://www4.fe.usp.br/estagios/manual-do-estagiario. Acessado em 20 jun. 2017.

2 Disponível em: www4.fe.usp.br/programa-de-formacao-de-professores. Acessado em 20 jun. 2017.

3 Idem, ibidem.

4 Disponível em: http://www4.fe.usp.br/wp-content/ uploads/programa-de-formacao-de-professores/ portaria-de-estagio-09.16.pdf. Acessado em 20 jun. 2017.

\section{Referências Bibliográficas}

BRASIL. Lei $n$. 11.788/2008. Dispõe sobre o Estágio de Estudantes. Disponível em: $>$ http://www.planalto.gov.br/ccivil_03/_ato2007-2010/2008/lei/111788. $\mathrm{htm}>$. Acessado em 24 abr. 2017.

CONSELHO ESTADUAL DE EDUCAÇÃO. Deliberação CEE n. 111/2012. Fixa Diretrizes Curriculares Complementares para a Formação de Docentes em Estabelecimentos de Ensino Superior Vinculados ao Sistema Estadual. Disponível em: <http://www. fct.unesp.br/Home/Graduacao/Pedagogia/deliberacoes-cee-111-de-2012-e-126-de-2014.pdf $>$. Acessado em 24 abr. 2017.

. Deliberação CEE n. 126/2014. Altera Dispositivos da Deliberação 111/2012. Disponível em: 〈http://iage.fclar.unesp.br/ceesp/textos/2014/651-06-Delib-126-14-Indic-127-14.doc >. Acessado em 24 abr. 2017.

Resolução CNE/CP n. 02/2002. Institui a Carga Horária para a Formação de Professores da Educação Básica. Disponível em: <http://portal.mec. gov.br/cne/arquivos/pdf/CP022002.pdf $>$. Acessado em 24 abr. 2017.

FACULDADE DE EDUCAÇÃO DA USP. $M a-$ nual do Estagiário. Faculdade de Educação da Universidade de São Paulo, São Paulo, 2015. Disponível em: $<$ http://www4.fe.usp.br/estagios/manual-do-estagiario>. Acessado em 20 abr. 2017.

Portaria de Estágio - Portaria FEUSP $n$. 09/2016. Faculdade de Educação da Universidade de São Paulo, 2016. Disponível em: <http://www4.fe.usp. br/wp-content/uploads/programa-de-formacao-de professores/portaria-de-estagio-09.16.pdf $>$. Acessado em 20 abr. 2017.

Projeto Pedagógico das Licenciaturas. Disponível em: <http:/www4.fe.usp.br/wp-content/uploads/ programa-de-formacao-de-professores/projeto-politico-pedagogico-das-licenciaturas-2014-em-vigencia.pdf $>$. Acessado em 24 abr. 2017.

Projeto Pedagógico da Pedagogia. Disponível em: <http://www4.fe.usp.br/wp-content/uploads/programa-de-formacao-de-professores/projeto-politico-pe- 
dagogico-da-pedagogia-2012-em-vigencia.pd $>$. Acessado em 24 abr. 2017.

UNIVERSIDADE DE SÃO PAULO. Programa de Formaşão de Professores. Pró-Reitoria de Graduação,
2004. Disponível em: 〈http://www4.fe.usp.br/wp-content/uploads/programa-de-formacao-de-professores. pd†. Acessado em 24 abr. 2017.

Publicado em 30/06/2017. 